\title{
RELAÇÕES DE GÊNERO E SUBJETIVIDADES NO DEVIR MST
}

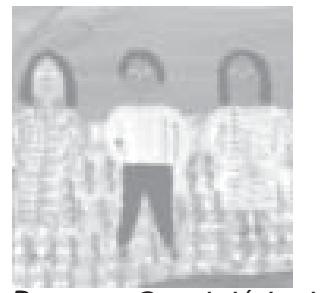

\author{
CRISTIANI BERETA DA SILVA \\ Universidade Federal de Santa Catarina
}

Resumo: Os relatórios internos e as diversas e distintas publicações do e sobre o MST produzidos nos últimos 20 anos desvelam processos que permitem perceber que outras preocupações foram constituídas em meio às lutas e disputas pela conquista da terra. Essas preocupações foram mudando, adquirindo outros contornos nas idas e vindas da produção de idéias, práticas e sujeitos de um Movimento em construção. Este estudo é um exercício crítico de reflexão sobre a natureza dessas produções nas relações cotidianas, nas tentativas de construir sujeitos militantes. Busca investigar como as mudanças foram sendo construídas e de que forma foram investidas sobre as relações de trabalho, sociais, políticas e, também, afetivas de mulheres e homens, bem como de homens e homens, e de mulheres e mulheres nas dobras do MST.

Palavras-chave: movimentos sociais, gênero, sujeito, subjetividades.

Em 20 abril de 1997, por ocasião de uma viagem de estudos, tive a oportunidade de conhecer um assentamento coletivo do MST chamado Conquista na Fronteira. Distante aproximadamente $800 \mathrm{~km}$ de Florianópolis, esse assentamento localizado em Dionísio Cerqueira, extremo Oeste de Santa Catarina, constitui-se como um 'cartão de visitas' para o MST. Ao longo da década de 1990 passou a receber muitas visitas, do Brasil e do exterior, sendo citado como exemplo de assentamento bem-sucedido, não só por lideranças ou publicações do Movimento, mas também fora dele. ${ }^{1}$

Nessa primeira visita, entre as conversas que tivemos, algumas lideranças, tanto masculinas quanto femininas, destacaram a preocupação do Movimento em relação às mulheres. Segundo suas falas, faltava ainda "resolver o problema da mulher", ou seja, sua suposta resistência em ocupar seu "lugar político" dentro do assentamento. Para essas lideranças, o não-envolvimento político das mulheres na luta era um problema que estava prejudicando o desenvolvimento do Movimento e, naquele momento em especial, o próprio assentamento.

Copyright (c) 2004 by Revista Estudos Feministas

${ }^{1}$ Apenas para ilustrar: na revista Globo Rural de abril de 1996 e no jornal O Estado de São Paulo de 20 de abril de 1997, o assentamento Conquista na Fronteira foi apontado como "modelo de reforma agrária". 
No decorrer dos caminhos ou descaminhos da pesquisa que implementei a partir dessas preocupações - e que acabou resultando em uma Tese de Doutorado em História ${ }^{2}$ - o 'problema' da e com as mulheres no assentamento Conquista na Fronteira, ao contrário de encerrar a questão em si mesma, desdobrou-se de várias e diferentes maneiras, de modo que o problema passou a ser percebido no interior de um jogo de posição/oposição e acabou por dimensionar as complexas relações de poder vividas por homens e mulheres nesse espaço, e na verdade para além dele também. Essas relações implicavam a leitura de hierarquias e ordenamentos de um universo singular e ao mesmo tempo plural. E a leitura que foi realizada no processo de construção deste trabalho procurou não confirmar essas hierarquias como permanências estruturais irredutíveis da construção dos gêneros, mas sim como possibilidades de conhecimento e reflexão do lugar dessas construções nas subjetividades de ser, de viver um projeto político ideológico.

As relações de gênero no interior de produções subjetivas em acampamentos e assentamentos do MST são muito significativas no conjunto dos discursos e práticas que as constituem. Em primeiro lugar, porque uma das preocupações do Movimento a partir de 1980 foi incorporar algumas discussões de orientação feminista bastante fortes nessa década. Depois, porque se investiu muito nas mulheres como sujeitos militantes, com direitos, mas sobretudo deveres no interior do Movimento. Essas preocupações, de certo modo, também reconstituíram partes dos discursos de "igualdade" e "emancipação feminina" que marcaram presença nos enunciados socialistas a partir do século XIX.

No MST, investimentos em busca de uma "sociedade ideal", de relações "igualitárias", foram sendo (re)produzidos constituindo devires em um Movimento que se pretende novo e capaz de mudanças. Nos primeiros anos de 1980, ocorreram várias reuniões de estudos e discussões entre lideranças do MST que, entre outras coisas, registraram em seus relatórios que a "pouca" participação feminina era um problema que o Movimento precisava resolver. E em um ir e vir de teorias e práticas recortadas e reconstituídas os investimentos feitos na perspectiva de resolver essa questão acabaram aparecendo nos acampamentos e, principalmente, em assentamentos ao longo dos anos.

Outros estudos já chamaram a atenção para essas singularidades de gênero nesse espaço: Noêlle Marie Paule Lechat observa e descreve a participação das mulheres na construção e organização de dois assentamentos do MST no Rio Grande do Sul na década de 1980. Esse processo não deixou de contar também com lideranças falando sobre a falta de participação das mulheres, destacando como causa sua falta de consciência política. ${ }^{3}$ Dulcinéia Pavan, em seu trabalho sobre mulheres em um assentamento no Estado de São Paulo, percebeu que as mulheres possuíam um papel de maior destaque em acampamentos e assentamentos do $\mathrm{MST}^{4}{ }^{4}$ Elisete Schwade vai além ao observar que o empenho em se construir a igualdade nesses espaços revelou dificuldades justamente quando se tentou viver essa construção nas relações do cotidiano. ${ }^{5}$

A partir desses olhares, o óbvio torna-se singular demais para que não seja percebido e pensado, mas, como bem lembra Paul Veyne, "espantar-se com o que é óbvio" não deixa de ser uma característica do esforço do historiador. Os militantes do MST são indivíduos inseridos em uma esfera complexa de relações sociais, sexuais e étnicas, inscritos de

\footnotetext{
${ }^{2}$ As fissuras na construção do"novo homem" e da "nova mulher": relações de gênero e subjetividades no devir MST - 1979-2000 (Cristiani Bereta da SILVA, 2003).

${ }^{3}$ LECHAT, 1993.

${ }^{4}$ PAVAN, 1998.

${ }^{5}$ SCHWADE, 1993.

${ }^{\circ}$ VEYNE, 1998, p. 21.
} 
múltiplas formas em um sistema geral de correlações de forças. Pensar, portanto, o lugar das relações de gênero em acampamentos e assentamentos é, aqui, um exercício crítico de reflexão sobre o poder, a igualdade, a transformação, o novo, elementos regulares que substanciam os discursos do MST. Esse é um exercício que busca perceber se esses mesmos elementos, reconstituídos em processos produtores de subjetividades, vêm deslocando ou reposicionando hierarquias e concepções naturalizantes entre mulheres e homens.

\section{Devires... a construção de sujeltos e movimentos}

A primeira invasão lembro como se fosse hoje... Foi bonito, chegou a dar uma emoção na gente porque aquilo tu olhava era gente com carroça, era com caminhão, era gente a cavalo, até meu pai foi com a carroça pro acampamento. Nós ficamos, e no outro dia cedo nós fomos, porque era perto de onde nós morávamos. Mas foi bonito o dia, deu uma emoção que tá louco! De ver eles indo, com bolsa e tudo! (Eliane. Casada, três filhos. Entrevista concedida em 03/09/1999).

No dia 7 de setembro de 1979, 110 famílias sem terra montaram acampamento na gleba $^{8}$ Macali, Rio Grande do Sul. Em maio de 1980, 300 famílias acamparam na fazenda Burro Branco, em Campo Erê, Santa Catarina. E em meados de 1980 Eliane era uma menina que, sem escolhas, já fazia parte das lutas e disputas pela terra que estavam sendo travadas no Oeste catarinense.

O pai de Eliane, como muitos outros trabalhadores rurais sem terra naquele momento histórico, estava animado com a possibilidade de conseguir um pedaço de terra, principalmente com as notícias das mobilizações que vinham acontecendo no campo: Macali e Brilhante, no Rio Grande do Sul; Burro Branco, em Santa Catarina. Assim, passou a se organizar junto com outros companheiros e, seguindo as estratégias políticas indicadas nesses grupos, acabou por levar sua família a participar das lutas pela terra em sua região, ou seja, foram fazer parte das ocupações e tornaram-se acampados.

Durante esse período, Eliane e suas irmãs viviam como todas as outras crianças acampadas: entre poucas brincadeiras infantis e muitas tarefas domésticas, entre cuidados com os pequenos e outros 'auxílios' prestados aos mais velhos, vivenciava as angústias daqueles momentos tensos. Eram cotidianos de dificuldades, em que as precárias condições de saúde, higiene, esperas por cestas básicas e outras doações em alimentos ou roupas, além do frio, da chuva, da lama... ditavam o ritmo de vida.

Aos 7 anos de idade, viu o pai ser preso por resistir à reintegração de posse da fazenda em que estavam acampados no município de Palma Sola, extremo Oeste do estado catarinense. Suas lembranças, narradas, ilustram uma parte das angústias e aflições reconstituídas de sua infância:

O pai foi preso... Ficou quase dois meses preso, e a mãe grávida com todos nós pequenos. Eu e mais uma menina, uma menina e mais grávida de outra, ficou sozinha... ainda que o pessoal ajudava... que se vinha tormenta e chuva e nós debaixo da lona, caía tudo, e o pai preso, eu perdi tudo, perdi a minha infância...

\footnotetext{
${ }^{7}$ Todas as entrevistas foram realizadas em Dionísio Cerqueira/SC. E com a finalidade de proteger a identidade dos/as entrevistados/as, neste artigo os nomes reais foram substituídos por nomes fictícios.

${ }^{8}$ As glebas de Macali e Brilhante eram terras remanescentes da antiga fazenda Sarandi, localizada no município gaúcho do mesmo nome e que foi desapropriada em 1962 pelo governador do Rio Grande do Sul no período, Leonel Brizola.
} 
Foi triste porque não aprendi a ler, nada, nem escrever. Ficamos todos esses anos debaixo da lona, não tinha professor, nada, e daí fomos embora, meu pai cansou porque estávamos muito pobres, não tinha nem o que comer, daí ficamos três anos na cidade e meu pai voltou de novo... (Eliane).

Eliane não aprendeu a ler, não aprendeu a escrever, passou - entre idas e vindas "quase sete anos debaixo da lona". Cuidava dos "menores", ajudava a mãe e casou-se, como tantas outras moças conhecidas suas, bastante jovem. Só que casou com um homem que sonhava, assim como seu pai, em conquistar também seu "pedaço de chão". E, talvez com as mesmas ou nenhuma escolha quanto às que teve em sua infância, passou a participar de ocupações no Oeste de Santa Catarina ao lado do marido e dos filhos pequenos.

Eliane passou grande parte de sua vida vivenciando tempos diversos, experiências distintas no interior do MST: foram tempos de dificuldades e angústias, mas também de esperanças, conquistas. Tempos em que cresceu, viveu, casou, teve seus filhos, tempos de idéias e ações em construção. Processos que constituíram e substanciaram um Movimento que hoje conhecemos como Movimento dos Trabalhadores Rurais Sem Terra. Um lugar que, através das lutas e reivindicações dos homens e das mulheres que o constituem - em sua heterogeneidade -, tem possibilitado questionamentos e reflexões sobre práticas excludentes e hierárquicas que seguem naturalizando as diferenças entre os sujeitos e suas relações ao longo da história.

É a partir desse lugar, de uma ponte entre o que foi vivido em meados de 1980 e sobre o que se pensa e se atribui ao MST 20 anos depois, que Eliane reconstitui suas lembranças, que fala sobre um antes e um depois, estabelecendo o MST como um marco de mudanças. Eliane fala de seu passado com certa angústia, no entanto fala de seu presente com orgulho, faz questão de informar como tudo melhorou, mudou. "Eu acho que tudo mudou..." (Eliane).

Mudança. Nesse sentido, a fala de Eliane não é singular, já que dezenas de depoimentos e trabalhos sobre o MST falam sobre a mudança, sobre a construção de um "novo sujeito" a partir do momento em que se passa a fazer parte da luta. A Eliane menina que seguiu seu pai e mulher que seguiu seu marido fala a partir e do interior de um lugar político. Mas esse político, informado, sobretudo, pelo gênero põe em perspectiva outras dimensões.

Olha, eu pra dizer a verdade eu consegui mesmo descobrir que a mulher tem o mesmo direito que o homem, como qualquer um também. Que o mais grande e o mais pequeno tem o mesmo direito foi aqui mesmo. No assentamento eu fiquei mesmo por dentro do assunto, que a gente mulher como mulher tem que lutar, tem que ir adiante, não pode pensar só nas panelas, no fogão, e nos filhos e na casa (Eliane).

Tânia, assentada no Conquista na Fronteira, por exemplo, percebeu após seu envolvimento com o MST, que

Muda, a mulher é sempre mais valorizada quando tem o mesmo direito que o homem tem, na divisão de tarefas, na parte da participação das reuniões, nas definições da cooperativa, mesmo fora do assentamento, tem o partido político que a gente participa também, tantas outras coisas [...] que nem em casa o meu marido ajuda a tirar o leite, os afazeres de dentro de casa, já os irmãos dele não, e eles eram acostumados assim, só que nessas ocupações que a gente fez, na participação do Movimento a pessoa muda. Mesmo nas discussões eles vivem falando que se a mulher trabalha na roça o homem também tem o direito de trabalhar, ajudar em casa. Que se os dois participam na roça os dois têm que participar em casa e também na educação dos filhos (Tânia. Casada. Entrevista concedida em 02/09/1999). 
Noêmia, sobre o assunto, procura ser mais enfática:

Meu Deus! Não tem explicação, porque na verdade a gente não tinha nada claro, a gente foi criada de uma forma que tu não era esclarecida, e a partir que a gente foi pra essa luta, meu Deus do céu, como tu tem claro as coisas e mesmo como reivindicar os teus direitos de mulher e mesmo como pessoa diante da sociedade. Na verdade a gente tava lá na comunidade e achava que tudo era justo e na verdade não era. (Noêmia. Casada. Entrevista concedida em 03/09/1999).

Os homens, quando questionados, narram processos semelhantes. Nas falas masculinas também o MST, o antes e o depois, os cursos, a formação informam as fronteiras, os investimentos feitos em busca de mudar, transformar o sujeito militante.

Bom, eu acho que aqui na Cooperativa as mulheres têm um relacionamento um pouco melhor que nas outras comunidades tradicionais, pensado na agricultura. Aqui as mulheres têm mais condições de participar em função da forma como nós estamos organizados e também pelas discussões, pela visão, pelos cursos, pela formação que as mulheres aqui na Cooperativa têm... (Mário. Casado. Entrevista concedida em 16/02/1998).

Assim como não é apenas nas falas das mulheres que as mudanças surgem definindo tempos e fronteiras, também não é apenas sobre o gênero feminino que as mudanças, as subjetividades revertem-se em investimentos e aparecem em seus relatos. Paulo ficou acampado durante três anos em Abelardo Luz na década de 1980, e é a partir das lembranças dessa época que procura destacar alguns aspectos que o fizeram "pensar diferente":

Quando a gente não conhecia, não sabia de nada, a gente não se interessava. Depois tudo mudou. Eu acho que a minha consciência, a minha cabeça mudou muito.

[Em que sentido?]

No sentido político, organizativo, até na questão da consciência com as próprias companheiras. Porque quando tu vivia na comunidade, tu vivia assim, trabalhava, convivia com os companheiros da comunidade, mas tu não tinha uma consciência, um sentimento pelas pessoas. Mas pra mim o sofrimento que eu passei no acampamento mudou muito. A melhor escola da minha vida foi os três anos de acampamento. A forma de tu pensar, de trabalhar, até com os filhos da gente. Eu não tinha um conhecimento de como é que podia ser um pai de família, mas, com o passar do tempo, você aprende a dar valor para os filhos, para a família, para os companheiros. [...]

A gente aprendeu muito nos cursos também a valorizar as mulheres, a se valorizar. A gente trabalha muito as relações humanas, o que eu faço e o que o outro faz, pra aprender a dar valor. Eu aprendi muito no acampamento e depois no assentamento. Em casa com a mãe eu procurava ajudar, mas depois a gente se conscientizou que tem que fazer de tudo na vida, aprender a fazer de tudo. Não é fazer o que tem na lavoura e a mulher além da lavoura fazer em casa. Não. Aí é que mudou bastante, dar valor ao trabalho que elas fazem (Paulo. Casado. Entrevista concedida em 10/01/2001).

Essas falas são de moradores do assentamento Conquista na Fronteira, homens e mulheres que, por seu trabalho, dedicação e, principalmente, esforço em não destoar das propostas do MST, fazem desse espaço referência de sucesso. Em um primeiro olhar essas falas poderiam até mesmo servir de 'evidências' que legitimam as propostas que o MST vem se colocando e discutindo ao longo de sua história. Isso significaria até mesmo dizer que o 'homem novo' e a 'sociedade ideal' já estariam sendo vivenciados em alguns 
espaços privilegiados no interior do MST. A subjetividade, essencialmente fabricada, modelada no registro do social, poderia então ser pensada sem maiores dificuldades. Mas é necessário ir um pouco além desse primeiro olhar e perceber que as produções subjetivas não são processos tão simples ou mesmo evidentes.

São as reflexões de Félix Guattari e Suely Rolnik que não permitem ilusões; chamam a atenção para o fato de que "não existe uma subjetividade do tipo 'recipiente' em que se colocariam coisas essencialmente exteriores, as quais seriam 'interiorizadas'". 9 Caso o processo fosse visto dessa forma, retiraríamos toda a sua complexidade e, além disso, ignoraríamos a capacidade das pessoas em escapar de normas e prescrições que thes dizem como ser e agir. Em meio às falas, aos gestos, e até ao visível, delineiam-se outras questões significativas e singulares nas dobras do devir MST.

O MST foi e ainda é um espaço onde diferentes discursos e práticas são investidos sobre os sujeitos que o constituem, discursos cujos efeitos acabaram se encontrando de maneira bastante significativa - bem onde muitos deixam de procurar - nas relações de gênero. Práticas prescritivas, disciplinares foram sendo construídas e (re)produzidas como investimentos sobre os homens e as mulheres, sobre suas relações familiares, políticas e afetivas. Esses investimentos para Eliane são lembrados sob um olhar singular. Mas as falas, as lembranças de Eliane, Tânia, Noêmia, Paulo, entre outras, tanto revelam quanto ocultam. O desejo de 'mudar', 'transformar', tem percorrido caminhos que descortinam perspectivas e expõe fissuras tanto no desejo quanto nos investimentos de se construir o 'novo' no interior do MST.

Nesse exercício de interpretação ou de apoderação violenta ${ }^{10}$ pode-se vislumbrar a existência de conflitos nas relações entre homens e mulheres, conflitos esses que se fazem presentes a todo momento na convivência diária do assentamento, mas não são conflitos expressos em palavras ou gestos explícitos. Existem diversas e variadas formas para que cada um expresse sua (in)satisfação. Isso porque uma coisa é discorrer sobre a valorização das mulheres e as mudanças que ocorreram em suas vidas; outra é o dia-adia em casa, na roça, nas reuniões de núcleo, na Cooperativa, no relacionamento entre marido e mulher, entre vizinhos, entre lideranças e demais integrantes.

Perceber esses conflitos e tentar interpretá-los é fazer um exercício de observação e sensibilidade; é ir em busca das diferenças e não das semelhanças, mesmo em meio a tantas falas que dizem em uníssono como tudo mudou, melhorou e avançou; é perceber também as particularidades, as pequenas resistências diárias, especialmente por parte das mulheres. Isso porque o MST, na figura de seus líderes, Ihes sugere que sejam mais participativas, que privilegiem atividades no coletivo, políticas, etc., em relação a outras atividades.

Antes de tudo, faz-se imprescindível reforçar uma questão: a qualidade de vida dos homens e das mulheres que vivem nesse assentamento coletivo, assim como de muitos outros que procuram seguir as propostas do MST, não está sendo posta em discussão. Não existe aqui a pretensão de questionar a validade ou a legitimidade das propostas do MST, muito menos quando vivenciadas em acampamentos e assentamentos.

O que me propus durante o processo de construção da pesquisa, do qual este artigo é um recorte, foi refletir de que maneira essas propostas estão sendo produzidas e

\footnotetext{
9 GUATTARI e ROLNIK, 1999, p. 34.

${ }^{10}$ Para Foucault, a interpretação é uma relação muito mais de violência que de elucidação. "De fato, a interpretação não aclara uma matéria que com o fim de ser interpretada se oferece passivamente; ela necessita apoderar-se, e violentamente, de uma interpretação que está já ali, que deve trucidar, revolver e romper a golpes de martelo" (FOUCAULT, s/d, p. 15).
} 
vivenciadas por homens e mulheres no MST. Até que ponto acarretam mudanças em suas relações? O que permanece? Suas linhas de fuga frente às normas, reelaborações e, por que não, seus conflitos, pois se vive sim um sonho, mas nas durezas do cotidiano, nas pequenas coisas da vida, das relações, nos jogos de poder, nas contradições, nas heterogeneidades, enfim, na multiplicidade. Da mesma forma, também não se tem a pretensão de abarcar todos esses desdobramentos. Mas sim perceber e, principalmente, pensar uma pequena parte deles, réstias de luz, frestas, elipses, pedaços possíveis de um quebra-cabeça que talvez nunca seja encaixado.

Na primeira visita ao assentamento Conquista na Fronteira em 1997, que seria seguida de outras feitas nos anos seguintes, em uma conversa com uma das lideranças do Movimento, percebi sua preocupação em relação às expectativas criadas em torno dessa comunidade, pois não queriam apenas criar um cenário modelo de sua própria luta e sim construir um ideal de vida, de trabalho possível. Em meio a essa conversa, em que se admitia as dificuldades, os problemas advindos das propostas do MST, algumas questões foram apontadas como problemas, e entre elas, ocupando um lugar significativo entre ditos e não ditos, estava a "questão da mulher". Os mais de 800 km percorridos na volta a Florianópolis não foram suficientes para que algumas elipses fossem esquecidas.

Porém, em uma nova visita, em fevereiro de 1998, as elipses cederam lugar às palavras de uma liderança feminina do MST, residente no assentamento:

Eu acho que nós teríamos que fazer um trabalho, porque eu não tô sentindo na mulherada uma motivação em relação ao coletivo. Elas estão num negativismo incrível, já não se prontificam muito no trabalho, não na produção, mas de agarrar o coletivo, elas fazem por fazer. [...] Nas discussões elas participam, núcleo, assembléia, só que, se fosse pra elas se escapar, elas se escapavam. Tem todas umas normas pra participar... outra coisa: se tem uma coisa errada, elas, ao invés de dizer "pô, vamos acertar e tal", mas elas são as primeiras a dá-lhe pau. Eu tô preocupada com essa situação, porque as nossas mulheres têm oportunidades aqui que muitas gostariam de ter... (Carla. Solteira. Liderança no MST. Entrevista concedida em 16/02/1998).

As preocupações relatadas acima recaem sobre as mulheres do assentamento, pois para Carla não há dúvida quanto à importância do trabalho das mulheres, no entanto não estariam participando o suficiente da construção do coletivo, isto é, dos usos das propostas colocadas pelo Movimento. Segundo seu entendimento, "as mulheres teriam que fazer mais é em relação ao coletivo, amar, gostar desse coletivo" (Carla). Observa-se, aqui, a circulação de valores, noções, sobre a "construção do coletivo", ou seja, sobre a construção da sociedade articulada pelo MST.

Eu acho que o MST é um lugar que mais se discute e se tem todo um trabalho em relação para que as mulheres participem. Agora, eu olhando aqui na Cooperativa a gente sente assim, por isso eu reforço que tem que fazer a mulher sentir o gosto, sabe? Porque quando tu sente o gosto, a necessidade e coisa, tu rompe qualquer barreira, da família e coisa. Isso é uma conseqüência, tu deslancha. Agora elas assim, são acomodadas, é uma questão cultural também, a gente tem que entender isso. Porque aqui, se fosse olhar, quando é pra ir um curso ou coisa assim, elas colocam mil obstáculos (Carla).

É significativo o modo com que os discursos que circulam no interior do MST fazem recair sobre as mulheres a responsabilidade pelas coisas não estarem caminhando no sentido esperado. Quando se tem, na fala acima, uma referência à "questão cultural" relativizando o 'comportamento' das mulheres sobre sua 'pouca participação', evidenciase a recorrência de alguns elementos que também já estiveram presentes em muitos discursos políticos, principalmente aqueles ditos de 'esquerda', discursos que ora 
dimensionaram a importância para as mulheres em serem 'mães, esposas e donas-decasa', ora relegaram essas funções como 'não-produtivas' e, por isso, sem importância, em detrimento de uma participação política mais efetiva."

Ainda assim, as mulheres enquanto objeto de discursos e intervenções, muitas vezes foram percebidas e tratadas como ameaças. Exemplos disso podem ser observados na história do movimento operário no Brasil. Nas primeiras décadas do século XX, a participação feminina nas questões que envolviam o trabalho era considerada uma ameaça, "como se as mulheres, e não os capitalistas fossem o inimigo". ${ }^{12}$

Michelle Perrot, pensando sobre os "numerosos mal-entendidos" que separam o sindicalismo e o movimento de mulheres no início do século XX, contribui de forma importante para pensarmos melhor essa questão, pois, para esta historiadora, entre o sindicalismo e as mulheres existe mais do que um problema de falta de organização; há um "conflito sobre os modos de intervenção e expressão, recobrindo uma diferença de cultura e vida". 13

Uma outra singularidade também parece permear os discursos sobre a participação feminina na esfera política: o retorno ao 'mito' da mulher que tem a oportunidade do poder, mas não o aproveita. Joan Bamberger, em sua leitura do 'matriarcado', percebeu, nos mitos e rituais que o envolvem, que as mulheres aparecem sempre como não sabendo administrar o poder quando o possuem. É interessante notar a existência de certos resíduos desses mitos cadenciando algumas discussões sobre as mulheres, como se fosse uma forma encontrada de demonstrar que um dia o gênero feminino fracassou, foi incapaz de assumir o poder. ${ }^{14}$

Enquanto espaço, o assentamento conta com práticas, estratégias prescritivas, subjetivantes em função de uma proposta de vida e trabalho para seus moradores. Contudo, é importante perceber que em meio a esse processo as mulheres - e seus "mil obstáculos" para não participarem - são relacionadas, percebidas como o sujeito que não constrói o coletivo. O que se esquece, nesse caso, é que não se trata de um sujeito, o gênero feminino que "não constrói o coletivo", mas sim de uma pluralidade de sujeitos com vontades e anseios diferenciados, sejam eles homens ou mulheres.

A respeito dessa questão, o entendimento de Eder Sader sobre coletividade é bastante pertinente, pois, se há construções de espaços, ideais, valores e, principalmente, sujeitos, elas são, antes de tudo, resultado de muitas interações entre diversos e diferentes fatores "em processos de reconhecimentos recíprocos, e cujas composições são mutáveis e intercambiáveis. As posições dos diferentes sujeitos são desiguais e hierarquizáveis; porém essa ordenação não é anterior aos acontecimentos, mas resultado deles". ${ }^{15}$

Considerando essa perspectiva, é possível apreender melhor por que as cobranças em relação à construção de um sentido de coletividade partem e são reproduzidas por pessoas que ocupam posições de lideranças. Isso porque se sabe bem que, além de não se poder falar de tudo em qualquer circunstância, qualquer um não pode falar de qualquer coisa. É a ordem do discurso que privilegia a fala de um sujeito em especial. ${ }^{16}$ Nesse sentido, a fala da liderança - sujeito constituído em outro nível e autorizado, portanto, a

\footnotetext{
${ }^{11}$ Ver: Maria Valéria PENA, 1981, p. 175-193. E ainda: Susan BESSE, 1999, p. 143-155.

12 PENA, 1981, p. 188.

${ }^{13}$ PERROT, 1988, p. 212.

14 BAMBERGER, 1979.

${ }^{15}$ SADER, 1988, p. 55.

${ }^{16}$ FOUCAULT, 1998, p 9.
} 
identificar e falar sobre os problemas do grupo de modo exclusivo - não deixa de ser um discurso privilegiado.

Na medida em que são portadoras das palavras e representantes autorizadas do MST, as lideranças trazem consigo e fazem circular a todo momento propostas e ideais de um modelo de sociedade, de comportamento, o qual buscam incorporar - 'para dar exemplo'. Dessa forma, procuram reforçar esses valores entre os demais integrantes. Além disso, é importante pensar que, por representarem o MST em um nível diferenciado, essas pessoas e as posições que ocupam indicam hierarquias construídas em suas relações.

Trata-se de relações hierárquicas que se estabelecem a partir dos variados investimentos na informação e formação entre os integrantes do MST, sejam eles homens ou mulheres. Ou seja, o processo de formação do sujeito militante, iniciado já nos acampamentos, acaba por estabelecer e reforçar diferenças. As mulheres que não ocupam posições de liderança ou alguma função política delimitada - a grande maioria - atribuem o seu tão criticado silêncio nas reuniões à sua falta de estudos, falta de formação:

Hoje em dia estudar é uma coisa difícil, e antigamente era mais ainda. Às vezes o que atrapalha é a falta de estudo, de formação, o medo de a mulher participar, uma insegurança de falar errado, de falar o que não é pra falar. (Marina. Casada. Entrevista concedida em 16/02/ 1998).

\section{Percebem na prática como se dá essa relação:}

Se a gente não participa, a gente fica de fora, fica desinformada. Daí eu gostava de participar, eu nem percebi como é que eu fui mudando. Assim...com o correr do tempo, a gente não queria ficar fora de nada. Se a gente não vai numa Assembléia a gente fica desinformada. Se a gente não vai numa reunião de núcleo, fica desinformada. Porque meu marido não é de ficar contando, daí eu nem peço, porque se eu não fui, pra que ficar pedindo? Daí eu já participo, pra eu não pedir! (Lurdes. Casada. Entrevista concedida em 03/09/1999).

Presente nas falas percebe-se, também, o retorno a uma velha questão: as atividades circunscritas ao interior da casa sendo constituídas enquanto problema, entrave à participação política: "Na verdade elas mesmas colocam: 'Eu não vou, tenho vaca de leite, tenho os filhos, tenho roupa, tenho isso e aquilo...'”. Para muitos, a explicação está na certeza de que as mulheres não participam em função de suas responsabilidades 'domésticas', fato entendido como uma questão de 'prioridade'.

(...) o problema é tu ter prioridade. Porque claro que o serviço vai ficar mais mal feito do que da mulher, isso é natural. Que vai ficar roupa no canto, vai ficar (...) Mas o que é fundamental também pra gente, é isso, essas coisinhas do dia a dia da casa é mais importante do que tu ir fazer uma faculdade? Ou do que você ir numa mobilização, o que é mais importante? Que fique jogada por uma semana a casa, depois se limpa, não é coisa de outro mundo, mas elas colocam isso como coisa de outro mundo. Elas se dão o luxo de não ir numa reunião porque têm que fazer o pão (Marina).

As lideranças do assentamento, homens e mulheres, trazem a todo momento esses mesmos elementos, ou seja, atribuem o 'apego das mulheres às suas casas' à sua pouca participação nas atividades políticas. O argumento de Franco, liderança do MST, reforça de forma mais contundente a mesma questão:

Então, eu particularmente acho que a participação da mulher hoje no movimento sem terra, seja no Sindicato, seja em qualquer outra mobilização, está muito fraca, muito restrita, são mínimas. São um número muito mínimo de mulheres hoje que têm essa vontade de participar, não, até muitas, pelo conhecimento que eu tenho aqui internamente. Inclusive, não é falta de espaço, o que tá faltando é falta de vontade mesmo. No meu ponto de vista, eu acho que 
algumas coisas as mulheres têm, algumas condições básicas. Pegando a experiência nossa aqui, já se tem condições pra que a mulher possa participar. Então algumas coisas elas não refletem dentro da organização, elas vão se refletir lá na casa, no lar delas (Franco. Casado. Liderança no MST. Entrevista concedida em 17/02/1998).

Mas é interessante perceber também que as mulheres, que não ocupam posições de lideranças propriamente ditas, trazem as mesmas questões e reproduzem discursos equivalentes. A fala abaixo representa outras falas que, invariavelmente, possuem o mesmo conteúdo:

Muitas só pensam em fazer o serviço de casa, não saem, não dão importância pra participar mesmo das reuniões aqui. Só pensam em trabalhar, não pensam em sair e não pensam em ajudar o pessoal na reunião pra resolver os problemas. Que se elas saíssem pra participar, elas vissem a realidade, elas iam se conscientizar da realidade. Elas sabem que tem direitos e deveres iguais aos homens, só que não ajudam. Participam das reuniões, mas não ajudam, não dão idéia, que nem os homens que dão mais idéias (Maria. Casada. Entrevista concedida em 02/09/1999).

Essa fala ilustra muito bem uma das singularidades acerca da participação feminina nesse espaço: o conhecimento da ordem do discurso. As mulheres não "dão idéias", ao contrário dos homens, 'capazes' de expor as suas.

Uma das mulheres que participaram da organização das mulheres agricultoras no Oeste catarinense, no final da década de 1970 e início de 1980, e que mantém estreitas relações com os moradores do assentamento, falou um pouco sobre as tensões que envolvem o "falar" entre homens e mulheres. A fim de organizar um abaixo-assinado para ser levado por mulheres até Brasília, Zulma lembrou da indignação de alguns homens, e de um, em especial, que lhe disse:

Mas o que estas mulheres querem ir fazer sozinhas lá [Em Brasília]. Não sabem nem falar com o Presidente, com os governantes. Isso tinha que ir nós homens, no mínimo um junto pra poder falar (Zulma. Casada. Militante petista que na época trabalhava em Chapecó junto à Comissão de Orçamento Participativo. Entrevista concedida em 09/01/2001).

Mas não são reações restritas apenas aos homens. As mulheres também reagiam de forma semelhante, como destaca Mário:

[...] era tão difícil. Às vezes com muito trabalho nós conseguíamos trazer algumas mulheres para participar, para falar. Daí algumas diziam: "Que vergonha aquela louca lá em cima do palco gritando, porque não deixa um homem falar" (Mário).

Convém lembrar novamente que o 'falar em público' ainda se constitui em um exercício recente para a imensa maioria das mulheres, daí a própria dificuldade de organizar, ordenar seu discurso. Além disso, as mulheres, quando falam, ainda têm que lidar com outras complexas circunstâncias que estão alocadas no interior das relações de gênero. Quando falam, suas palavras dividem atenções com suas pernas e seios, além de, muitas vezes também, confundirem-se com sua própria vida íntima. Michelle Perroł escreveu sobre isso: "tão logo uma mulher toma a palavra, todos se preparam para se aproveitar de suas dificuldades. Sua voz, seus gestos, seu look, todo seu corpo é objeto de um exame em que predominam o irônico e o vulgar". ${ }^{17}$

Como a imensa maioria das mulheres do assentamento, Tânia concilia o 'ser' dona de casa e esposa com o 'ser' sócia da Cooperativa, onde - como também todas as outras

\footnotetext{
17 PERROT, 1998, p. 129.
} 
mulheres - trabalha meio período. Isso porque, segundo ela, há os serviços da casa que precisam ser feitos e as crianças que precisam de atenção. Perguntei, então, se ela 'participava', se ia às reuniões, ou a mobilizações:

Os homens saem mais, tem uns que saem mais.

[Por quê?]

É que é escolhida a maioria... a direção escolhe as pessoas que têm mais condições, se fosse olhar, de sair são os homens, porque as mulheres ficam com o serviço de casa...

[E tu, como é?]

Ah, eu, se for de sair, eu saio, mas eu por enquanto faz um tempinho que não saio mais porque eu tenho nenê pequeno, mais caseira que eu não tem. Se fosse olhar, não tem como sair, se fosse fazer um curso de levar o nenê junto ou deixar, já fica meio ruim, mas eu antes de ter nenê participava. E espero que depois que ele crescer eu também continue participando, porque eu gosto de participar das reuniões... (Tânia).

Conversando com um casal sobre esse assunto foi possível perceber que, se o homem não impede explicitamente que sua mulher vá a alguma mobilização, acaba demonstrando isso de outras formas: reclamando quando tem que fazer o serviço da casa, ou simplesmente não fazendo. O que indica que, se há resistência, não só as mulheres resistem, mas os homens também. "Existe isso também - 'se é pra mandar a mulher, então vou eu'. Uns porque gostam, uns porque não gostam que suas mulheres saiam" (Mário). Marina vê isso de modo mais claro: "É que eles não gostam de fazer o serviço de casa". E Mário, seu marido, conclui em tom de brincadeira: "O serviço nem que fique pra quando a mulher voltar..."

Comparando essas falas e também outras, muitas questões se fazem presentes. A mais simples é o fato de trazerem consigo os mesmos elementos, ou seja, o problema é da mulher que não participa, e não o faz em função da casa e dos filhos. Mas será mesmo que essa questão é simples? Certamente que não. Pois é uma questão que vai além do político, e muito além do fato de as mulheres se negarem a 'participar', de resistirem às prescrições, às normatizações de como deveriam ser para representar o Movimento.

Primeiramente, temos a casa, o lar, em perspectiva, um espaço que encerra em si mesmo um emaranhado de significados relacionados ao feminino. Assim, a casa para as mulheres do assentamento tem um valor muito especial. Para muitas delas, depois de anos morando em barracos de lona ou outro tipo de material, cozinhando em fogões improvisados, utensílios escassos e nenhum conforto, foi a primeira conquista de um espaço próprio, onde puderam depositar finalmente seus sonhos, suas 'quinquilharias'. Um território íntimo, no qual elas podem exercitar seus 'pequenos poderes', e onde não se sentem inseguras ao falar, ao agir.

Além disso, a casa é mais que uma construção material; é, sobretudo, social, cultural e, por isso mesmo, "não pode ser aceita como natural e evidente por si mesma". Como fronteira entre as "esferas masculinas e femininas" ou entre a dicotomia público/privado, esse espaço tem servido às "mulheres como local de aprisionamento e de responsabilidades sociais. Torna-se necessário revelar o exterior para o interior e vice-versa, desconstruindo

\footnotetext{
${ }^{18}$ Thomas FOSTER, 1988, p. 73-99. Tradução livre.
} 
os limites entre o público e o privado, rejeitando a casa como mecanismo de exclusão". ${ }^{18}$

Entretanto, o que vemos perpassar nas relações entre as mulheres e os homens do assentamento Conquista na Fronteira - na verdade, também para além desse espaço, pois a "metáfora das esferas separadas", mesmo erodidas, ainda flui fortemente no interior de muitas outras casas - é o fato de que o 'lar' e suas inúmeras responsabilidades acabam sendo 'deixados' pelos homens às mulheres. "Queira ou não queira eles acham ruim a mulher sair de casa. Porque tem a casa, tem os filhos, tem a roupa, e tem o costume de chegar e a comida tá pronta, tem muitos homens que acham difícil ficar sozinho" (Maria Tereza. Casada. Entrevista concedida em 17/02/1998). Ou seja, circunscrevendo as tarefas domésticas ao feminino, os discursos sobre as mudanças de comportamento no assentamento trazem a permanência de valores em que 'a casa' ainda se constitui como uma fronteira de gênero.

Mesmo em um espaço em que se discutem relações de gênero - e principalmente onde se questiona a participação das mulheres - é importante pensar que, se a casa pertence às mulheres, o resto parece pertencer aos homens. Isso porque se percebe, sim, uma divisão sexual de trabalho no cotidiano do assentamento, a começar pelas 'comissões', nas quais a Saúde e as 'Miudezas' são dirigidas por mulheres, e o setor de Produção e Finanças, por homens. Na eleição da Cooperativa, realizada no segundo semestre de 1999, a Presidência foi composta por 5 homens e nenhuma mulher.

Os trabalhos 'leves' pertencem às mulheres e os 'pesados' aos homens, mesmo que muitas vezes esses limites sejam tênues, transpostos e que os trabalhos não sejam tão 'leves' assim. ${ }^{19}$ Lixar o fogão a lenha, por exigir 'força', assim como cortar lenha são trabalhos atribuídos aos homens, mesmo que muitas mulheres executem essa tarefa diariamente: "aquele serviço mais pesado, que é lascar lenha, essas coisas os homens fazem [...] arrumar um galinheiro, uma estrebaria que tá quebrada, essas coisinhas do individual que é feito mais no final de semana" (Carla). Já ordenhar as vacas, que as famílias têm individualmente, é uma tarefa entendida como feminina. Mas é interessante perceber que o 'ordenhar' é invocado pelas mulheres sempre que querem atestar a qualidade de seus respectivos maridos. Idalina, por exemplo, não deixa de lembrar as qualidades de seu marido, afirmando que ele "tira leite, faz tudo, lava até as roupas" (Idalina. Casada. Entrevista concedida em 17/02/1998). Noêmia também: "em casa o meu marido ajuda tanto a tirar - leite quanto os serviços de dentro de casa" (Noêmia. Casada. Entrevista concedida em 03/09/1999).

O cuidado com a grama parece ser responsabilidade dos homens no assentamento. Carla passou essa impressão ao mencionar o fato de as mulheres reclamarem da ausência do marido, nos finais de semana, para executar essa tarefa: "entre atender uma visita que vem de fora e você cortar a grama, o que é fundamental? Por mais que esta carga te fique, porque o que é mais importante na nossa luta é tu ir lá atender a visita, fazer uma discussão, ou tu ir cortar a grama ao redor de casa?".

Na roça, por onde andei algumas vezes, vi mulheres carpindo e homens dirigindo tratores. Mário falou um pouco sobre isso: "os trabalhos que as mulheres aqui na Cooperativa não fazem eu acho que é operar as máquinas agrícolas, os demais elas fazem todos, elas passam até veneno, que é um serviço bastante complicado". Perguntei a algumas mulheres por que elas não operavam as máquinas, e elas riram, dizendo que era porque não queriam, mas acrescentaram que, se quisessem, poderiam.

É significativo o fato de que, mesmo aquelas mulheres mais distantes das posições

\footnotetext{
${ }^{19}$ Maria Ignez PAULILO, 1987, p. 64-70.
} 
estratégicas de comando não passam a idéia de submissão ou passividade. Elas parecem negociar entre si e com os homens seu próprio espaço, não o imaginado por algumas lideranças, mas um que até agora conquistaram, e que cada uma preserva à sua maneira. Informadas de seu espaço, as mulheres muitas vezes o aceitam, até mesmo porque ninguém mais do que elas sabe de seus medos, de suas inseguranças e certezas. E talvez saibam mais, talvez sintam que, se quisessem mesmo ser militantes exemplares, ou operar máquinas agrícolas, teriam que fazer isso e continuar fazendo tudo o mais que vinham fazendo. É bom não esquecer que as mulheres aprenderam a se diferenciar se afirmando por outras palavras, outros gestos...20

O que chama a atenção também nas falas dos moradores do assentamento Conquista na Fronteira é que, como um espaço onde procuram privilegiar ideais de comportamentos, os conflitos entre vizinhos e vizinhas e os problemas entre os casais saem do foro íntimo e tornam-se assuntos comentados e debatidos politicamente. Casos de esposas que brigam com os maridos pelo fato de não quererem que eles 'participem muito' são bastante comuns. Todos parecem saber, escolhem 'um lado' para dar razão e até discutem possíveis soluções para os casos.

O conjunto de normas, códigos disciplinares, entre outros documentos prescritivos do MST, aborda múltiplos aspectos que dizem respeito ao jeito de ser, de fazer, de homens e mulheres militantes. O militante, segundo esse conjunto de normas, precisa ser honesto, companheiro, trabalhador, zelador e respeitador das normas e princípios do Movimento, ter consciência política, respeitar a família, entre tantos outros valores e atitudes.

O assentamento Conquista na Fronteira, assim como outras cooperativas do MST, também possui um regimento de regulação interna. $\mathrm{O}$ artigo XXIV do Regimento Interno desse assentamento dispõe de normas específicas sobre relacionamento e comportamento pessoal que acabam indicando os limites nas relações entre os sujeitos. Ao lado das inúmeras disposições que visam a regular as relações entre os integrantes do Movimento, existem aquelas mais específicas que recaem sobre a vida íntima de cada um. $O$ item " $g$ " desse artigo especifica: "É compromisso de todos os casais manter um bom relacionamento conjugal para fortalecer a organização". ${ }^{21}$ Nesse sentido, o artigo XXVII, que prevê punições para uma série de transgressões, coloca a prática de "atitudes imorais", como por exemplo o adultério, como passível de punição.

Certamente existem 'conversas' paralelas, fofocas, que, servindo também como instrumento normativo de condutas, trazem alguns elementos significativos. Problemas matrimoniais são alçados como parte das preocupações da comunidade. O adultério é tratado como caso de 'indisciplina' e acaba recebendo punição severa, como um afastamento temporário ou até definitivo do assentamento. Em um desses 'casos', que envolveu dois casais do assentamento ("a mulher de um que se envolveu com o marido de outra"), o que chama a atenção é o fato de a pena ter recaído apenas sobre a mulher que se viu 'convidada' a passar um tempo fora do assentamento para 'pensar' na sua atitude. A justificativa, dita entre conversas miúdas, para que só a mulher tenha sido punida parece estar relacionada ao fato de ela ter fama de ser 'faceira'. Para alguns, a culpa não era do homem, mas sim da mulher, que tinha o "hábito de se oferecer".

A mulher, depois de um tempo fora, voltou para o assentamento e para seu marido. O outro casal já estava vivendo sem maiores problemas, já que o homem havia sido 'inocentado'. Em outras visitas, vim a conhecer e mesmo a conversar com as personagens dessa história, ocasião em que precisei descontruir as imagens e versões que minha

\footnotetext{
20 PERROT, 1988, p. 212.

${ }^{21}$ MST, 1997.
} 
imaginação havia construído. Evidentemente, não vi a mulher 'faceira', o homem 'seduzido', os parceiros 'traídos', mas sim homens e mulheres vivendo suas vidas, parecendo mesmo alheios às lembranças e referências sobre sua história íntima nas conversas dos outros companheiros e companheiras do assentamento.

Hoje penso que, além de esse caso ilustrar, e muito, alguns preconceitos que carregamos sobre as relações afetivas e, em especial, o comportamento feminino nessas relações, a não-punição do homem também passou por uma relação de poder mais complexa, pois ele ocupava um lugar de liderança, e a mulher não. Até para não desmoralizar o regimento, era importante que a comissão disciplinar aplicasse alguma pena, a qual teria que recair naquele cuja ausência seria menos onerosa para o assentamento. Mas, e se ela fosse a liderança, o que teria acontecido?

Nas conversas que circulam pelo interior do assentamento, há também as queixas sobre a falta de compreensão das mulheres acerca das atividades de seus respectivos maridos quando estes ocupam ou são indicados para posições de liderança.

Mas assim, por exemplo, se meu marido é escolhido pra ser da direção e tal, eu me orgulharia. As mulheres aqui não, ficam bravas... mas saem bufando da Assembléia porque o marido assumiu. Mas é um orgulho ter um marido que faz isso, que prioriza mais a Cooperativa do que a família. Eu acho que do ponto de vista ideológico, do que a gente quer, que bom que ele prioriza mais o coletivo do que o individual. Mas elas xingam... Tem homens que tão na direção ficam tudo assim ao assumir uma coisa no final de semana... "Ah, não posso, senão minha mulher fica brava" (Carla).

Essa questão parece estar bem presente no cotidiano de muitos casais do assentamento. Para Orlandi, é simples descrevê-la:

No momento que o homem assume o compromisso que tem que sair, porque ele vai num regional, que ele vai ficar mais fora, a mulher, na própria discussão com a direção já é colocado isso, que ela vai ter que se acostumar com a idéia porque agora ele está na direção. Por tanto tempo ele vai ficar mais ausente do que em casa. [...] No começo é difícil da mulher se acostumar, um homem que nunca saiu e aceita um compromisso assim, mas depois não tem problema algum (Orlandi. Casado. Entrevista concedida em 16/02/1998).

Tanto homens quanto mulheres, ao falarem de alguns conflitos que emergem em seu cotidiano de relações afetivas e políticas, nos trazem elementos que nos remetem a estas questões:

Minha mulher não quer que eu viaje, ela tem essa resistência. Ela não se acha que eu tenho o direito de estar viajando, tá indo num encontro. Ela sendo uma pessoa isolada, ela acha que ela, que vive somente na casa, ou aqui na Cooperativa, ela acha que isso não é justo. $E$ eu, particularmente, não sei se o que eu estou fazendo tá sendo correto ou não tá, mas eu tô trabalhando pra isso. Ela tá começando a estudar, tô incentivando e procuro incentivar pra ela participar dos cursos quando há oportunidade...

[Mas e se fosse o contrário, Franco, e se fosse você que ficasse aqui e ela fosse 'liberada'?] ${ }^{22}$

Não teria nenhuma restrição. Agora tem uma coisa concreta que é a seguinte: existe uma resistência maior no meu caso porque eu acho que ela vai tá roubando meu espaço. Quando se tem uma família, essa é a coisa concreta. Quando se tem uma família, se ela participar $90 \%$ do tempo significa que eu vou ter que ficar em casa.

22 'Liberados' são todos aqueles líderes, já assentados, que são liberados de suas atividades na produção para poderem viajar, participar de cursos, organizar acampamentos, mobilizações, entre outras atividades. 
Quando Franco acusa sua esposa de resistência e fala que, apesar de seus 'esforços', ela parece continuar não querendo participar das atividades propostas pelo MST - e também fala sobre a manifestação contrária da mulher, para com suas idas e vindas como liderança -, ele vai além de nos deixar vislumbrar alguns aspectos de seus conflitos com a esposa. Na verdade, traz pontos significativos que permitem pensar na dimensão hierarquizante, na qual estão alocadas as relações de gênero.

Mesmo se esforçando para incorporar as idéias do MST - no qual, inclusive, é uma das lideranças mais participativas -, Franco, o tempo todo, reproduz valores bem delimitados acerca da assimetria existente entre sua mulher e ele, o homem. Aqui, parece que seu 'espaço' sempre existiu, que não precisou ser problematizado; ao contrário do 'espaço' de sua mulher, constantemente alvo de discursos, preocupações e pressões. Retorna-se aqui à metáfora das "esferas separadas", pois as mulheres ainda parecem pertencer a uma "esfera feminina". Já os homens, de certa forma, pertencem ao resto das coisas e das ordens do mundo social: "homens nunca tiveram uma 'esfera própria', porque sua esfera tem sido o mundo e todas as suas atividades". ${ }^{23}$

Dessa forma, é preciso considerar novamente a reprodução nos assentamentos de sistemas e valores sociais e culturais vividos há muito tempo, tantos pelas mulheres quanto pelos homens. E mais do que isso, é necessário dar-se conta das muitas temporalidades possíveis e coexistentes em um mesmo espaço, perspectiva que indica que, ao lado das mudanças, temos também permanências.

Falar sobre permanência, quando se fala tanto em mudanças, levanta questões importantes, pois, ao contrário do que possa parecer, significa pensar, sim, a mobilidade, a pluralidade das relações sociais, culturais. Isso porque dimensiona a todo momento a capacidade que temos de negociar valores, ocasião em que trocamos e invertemos situações, mesmo tendo como referências certas hierarquias, sejam elas de classe, de gênero, de etnia ou de geração.

Neste momento, talvez seja pertinente pensar um pouco a respeito da 'universalidade' de certos valores. Estudos, ditos estruturalistas, já dedicaram bastante o seu tempo pensando as semelhanças, as estruturas que ordenam o mundo social. Para Louis Dumont, a hierarquia é uma questão central, uma necessidade lógica do ordenamento social. Estudando as castas na Índia, Dumont escreve que esse complexo sistema serve para nos ensinar "um princípio social fundamental, a hierarquia, cujo oposto foi apropriado por nós, modernos, mas que é interessante para se compreender a natureza, os limites e as condições de realização do igualitarismo moral e político ao qual estamos vinculados". ${ }^{24}$

As análises de Dumont, ao contrário de dimensionar a hierarquia como legítima, necessária para o 'ordenamento do mundo social', podem ser instrumentos valiosos para pensar as relações de gênero, como também relações de poder, relações que se localizam e são construídas a partir do pressuposto e da aceitação de uma ordem hierárquica do mundo.

Sob essa perspectiva, Maria Luiza Heilborn argumenta que não se deve entender a idéia da hierarquia como sendo um "traço tributável à tradição, na qualidade de uma sobrevivência" ${ }^{25}$ nas análises de gênero. No entanto, ela nos dá a possibilidade de perceber, através de suas análises, que, equacionada ao valor instituinte da cultura, a produção do masculino investe-se dos significados de representação da totalidade e, dessa forma, sobrepõe-se ao feminino nas relações.

\footnotetext{
${ }^{23}$ Linda KERBER, 1988, p. 6. Tradução livre.

24 DUMONT, 1992, p. 50.

${ }^{25}$ HEILBORN, 1998, p. 48.
} 
Para além de qualquer discussão sobre a universalidade de certas questões, ou seus resíduos na atualidade, é bom pensar também que, por alguma razão, os indivíduos precisam inventar 'seus outros', ou, no caso em questão, 'suas mulheres'. Para Félix Guattari, essa questão faz parte da segregação subjetiva que atravessa o corpo social, e que se localiza em um nível de projeção de fantasmas coletivos, onde estão os negros, os homossexuais, os pobres e, por que não, as mulheres em certas relações. ${ }^{26}$

Sobre isso, uma questão pode ser levantada acerca das mulheres do assentamento: tratar-se-ia apenas de uma forma de resistência, ou melhor, de escapar às normas? A pergunta admite duas respostas: sim e não. Não, porque, tendo como certo e dado seu espaço como sendo o da casa, e o cuidado com os filhos, e havendo por parte dos maridos uma contribuição para que assim permaneça, as mulheres não vêem muitas opções. Simplesmente entendem, de forma mais prática e menos ilusória, que precisam conciliar coisas políticas e domésticas, privilegiando aquelas mais importantes e necessárias segundo seus próprios julgamentos. No caso, muitas vezes, o lar e os filhos.

Sim, porque, de acordo com os objetivos expostos, elas talvez não queiram 'pela metade', ou seja, participar dos cursos, reuniões, etc. e depois terem que retomar todo o serviço de casa que acumulou nos momentos que passou longe. Ora, talvez aqui a resistência não seja ao MST, às suas propostas, ou à 'igualdade' de gênero, mas sim à sobreposição de responsabilidades e de trabalho.

Essa suposta resistência também pode estar relacionada à forma como é feita a 'divisão de renda' pela Cooperativa. Os homens, as mulheres e as crianças (a partir dos 12 anos de idade e que façam alguma atividade na Cooperativa no período inverso ao da Escola) que compõem o assentamento Conquista na Fronteira são sócios da Cooperativa de Produção Agropecuária União do Oeste (Cooperunião) através do sistema de cotas. A produção é coletiva; os sócios possuem uma renda que considera as horas que cada um se dedica à produção. Se o sócio ou a sócia trabalhar o período integral, recebe $100 \%$ do valor estipulado (os acertos de renda e subsistência são feitos de seis em seis meses e também ao final do ano agrícola, julho a julho).

Porém, as mulheres, em sua grande maioria - pelo menos até 2001 -, trabalham apenas meio período na Cooperativa; o outro é dedicado aos trabalhos da casa e à família. A Cooperativa entende então que essas mulheres têm direito a apenas $50 \%$ da renda. O período dedicado a casa pelas sócias não é pago, pois é entendido como trabalho particular, mas as mulheres vêm reclamando desse sistema desde sua implantação. A proposta para solucioná-lo surgiu do planejamento de uma 'cozinha coletiva', na qual todos fariam suas principais refeições. Mesmo assim, é uma proposta muito distante do ideal, pois não altera o fato de que 'serviço de casa', mesmo em um assentamento coletivo, é individual, e nesse plano cabe às mulheres fazê-lo.

Cuidar do 'bem-estar' da família, célula tão importante para o Movimento, deixa de ser um trabalho coletivo a partir do momento que, no interior das diferentes relações de gênero, é tarefa atribuída ainda apenas às mulheres. Trata-se de construções bem marcadas nesse caso, pois não só as mulheres deixam de receber pelas atividades dedicadas a casa, como também, ao se aposentarem, ganharão apenas metade dos rendimentos dos homens. O artigo XVI, do Regimento Interno da Cooperativa do assentamento Conquista na Fronteira, dispõe que "o associado a partir dos 55 anos que

\footnotetext{
${ }^{26}$ Guatarri fala que, "se os negros não existissem, seria preciso inventá-los de alguma maneira". E acrescenta que esse problema está localizado efetivamente na construção, na produção de subjetividades (GUATTARI e RONIK, 1999, p. 77-78).
} 
não têm condições de acompanhar o trabalho normal receberá uma ajuda pela luta e trabalho já aplicado de 30\% para o homem e 15\% para a mulher na divisão de renda e subsistência". ${ }^{27}$

Nas visitas e conversas feitas sobre essa distribuição de renda, as falas repetem-se esclarecendo que a 'questão' logo será revista. As mulheres costumam alegar que o problema está em vias de ser resolvido com a construção de uma cozinha comunitária. Foi o que disseram para mim em 1998, foi o que disseram para o repórter João de Barros, da revista Caros Amigos, em 2000, e foi o que disseram em 1990 para a antropóloga Elisete Schwade, que considerou a construção dessa cozinha como uma possibilidade de maior participação das mulheres no assentamento. ${ }^{28}$

Mas o que fica de tudo isso é a constatação de que as disposições que dizem respeito ao trabalho das mulheres nesse Regimento apenas têm sido alvo efetivo de discussão quando algum visitante mais intrometido fica sabendo como é feita a distribuição de renda da família. Em uma dessas ocasiões, em uma roda de chimarrão de final de tarde, mediante algumas provocações, duas mulheres - Marina e Zulma - contraargumentaram o tempo todo com seus maridos sobre a incoerência dessas disposições. Essas conversas acabaram esfriando quando Marina foi preparar o jantar com a nossa ajuda, a de Zulma e a minha, enquanto os homens 'trocaram o rumo da prosa' na espera do jantar...

Em conversas, com o gravador desligado, às vezes no final do dia, quando o 'políitco' ficava de lado para dar lugar a coisas menos 'nobres' - uma bicheira em uma vaca, um mutirão para a colheita do feijão do dia seguinte, um bicho de pé inflamado, uma doença diferente, algumas fofocas -, comentários sobre alguém sempre saíam. Nesses momentos, notava que homens e mulheres acabavam se despindo um pouco do 'ser militante' e teciam comentários segundo seus julgamentos bem pessoais. Foi interessante perceber, nas falas, que as lideranças femininas, as 'mulheres que falam', são identificadas com sua vida íntima: se são casadas, solteiras, separadas. Anotei alguns comentários em meu 'diário de viagem' ao longo de várias visitas e que são bastante ilustrativos. Sobre uma liderança solteira: "coitada, não casou ainda". Se separada: "essa aí se liberou, se liberou até do marido" (trocadilho com o termo 'liberado', muito utilizado entre a militância). Se casada: "o marido tem que acreditar muito na luta para ser casado com uma liderança".

Frases assim, ditas em tom de brincadeira, pilhéria, desvelam que os investimentos em produzir militantes, novos homens, mulheres, relações, andam por terrenos bastante movediços e imprevisíveis. Um ou uma militante do MST pode até ser exemplar, amar e acreditar na luta, não só pela terra, mas também pela transformação da sociedade, discursar em sintonia com as propostas, valores do MST, mas às vezes, ao final do dia, relaxados nas varandas de suas casas, ou na de um vizinho, tomando chimarrão, nada os impede de brincarem consigo mesmos e com seus companheiros e companheiras de luta e continuarem fazendo juízos de valores sobre comportamentos, jeitos de ser, associados a papéis normativos de gênero.

Nesses diferentes tempos, uma questão não pode ser esquecida: mesmo trazendo permanências, as mudanças fazem parte da história de vida e de luta dos homens e das mulheres que constituem o MST. Assim também como os conflitos, as diferenças fazem parte de um jogo de negociações, de trocas. Vi homens varrendo e lavando louça. Ouvi mulheres falarem de seus maridos com orgulho, pelo fogão lixado, pela roupa que um dia

\footnotetext{
${ }^{27}$ MST, 1997.

${ }^{28}$ SCHWADE, 1993, p. 140.
} 
ele lavou, pelo cuidado com os filhos, pelo tipo de relacionamento que agora elas reconhecem ser diferente de um tempo anterior. Ouvi homens e mulheres brincarem com algumas questões. Quando fazem algum trabalho que entendem como feminino, por exemplo, costumam repetir em tom de provocação: "Se as mulheres não queriam fazer esse serviço, porque inventaram então?"

Ele mudou, mudou bastante, ele era mais sossegadáo, eu que me lascasse no serviço. Hoje ele me ajuda. Aqui, todo homem ajuda a mulher. Aí não dá pra ficar um sem ajudar. Ele mesmo foi se sentindo... [...] Serviço de mulher era serviço de mulher, mas hoje não é mais assim. Às vezes ele diz, dando risada: "As mulheres aqui tão ficando muito 'baseada', querem que os homens façam tudo!" (Lurdes).

Já que normas, disciplinas, foram construídas, os sujeitos sujeitam-se, mas também escapam, negociam. Pelos interiores do MST por onde andei, distante, mas também com algumas proximidades com o que li, encontrei homens e mulheres, possuidores de sentimentos dos quais se orgulham, ou nem tanto. Encontrei neles, e em mim mesma, uma pluralidade de tempos, de desejos e micropoderes, coexistindo e sendo vivenciados em diferentes relações que se fazem entre sujeitos que reinventam a si mesmos. Apesar dos investimentos, dos controles, das disciplinas, os homens e as mulheres encontraram suas formas de seguir vivendo, de escapar, de incorporar algumas mudanças sutis. Eles e elas não deixam de persistir na construção de um novo tempo e de uma nova forma de pensar suas ações e a si mesmos na história, e também de simplesmente não pensar, só viver. Mas vão construindo, experimentando viver segundo seus próprios tempos, sentimentos, que afinal dão o ritmo às mudanças e às permanências, dos pequenos e dos grandes acontecimentos que fazem parte da história e da vida de cada um.

\section{Referências bibliográficas}

BAMBERGER, Joan. "O mito do matriarcado: por que os homens dominam as sociedades primitivas?" In: LAMPHERE, Louise; ROSALDO, Michelle Z. (Coords.). A mulher, a cultura e a sociedade. Tradução de Cila Ankier e Rachel Gorenstein. Rio de Janeiro: Paz e Terra, 1979. p. 233-254.

BESSE, Susan K. Modernizando a desigualdade: reestruturação da ideologia de gênero no Brasil, 1914-1940. Tradução de Lólio Lourenço de Oliveira. São Paulo: Edusp, 1999.

DUMONT, Louis. Homo hierarchicus: o sistema das castas e suas implicações. Tradução de Carlos Alberto da Fonseca. São Paulo: Edusp, 1992.

FOSTER, Thomas. "History, Critical Theory and Women's Social Practices: 'Women's time' and 'Housekeeping'." Signs. Journal of Woman in Culture and Society, Chicago: The University of Chicago Press, v. 14, 1988. p. 73-99.

FOUCAULT, Michel. A ordem do discurso. 4. ed. Tradução de Laura Fraga de Almeida Sampaio. São Paulo: Edições Loyola, 1998.

Nietzsche, Freud e Marx - Theatrum Philosoficum. Porto: Edições Rés Limitada, s/d.

GUATTARI, Félix; ROLNIK, Suely. Micropolítica: cartografias do desejo. Petrópolis: Vozes, 1999.

HEILBORN, Maria Luiza. "Gênero: um olhar estruturalista". In: PEDRO, Joana Maria; GROSSI,

Miriam Pillar.(Orgs.). Masculino, feminino e plural: gênero na interdisciplinaridade.

Florianópolis: Ed. Mulheres, 1998. p. 43-55.

KERBER, Linda K. "Separate Spheres, Female World, Woman's Place: the Rhetoric of Women's History." The Journal of American History, New York, v. 75, n. 1, June 1988. p. 9-39.

LECHAT, Noêlle Marie Paule. A questão de gênero no Movimento dos Trabalhadores Rurais

Sem Terra (MST): estudo de dois assentamentos no Rio Grande do Sul. 1993. Dissertação

(Mestrado em Antropologia) - Universidade Estadual de Campinas. 
MST. Regimento Interno da Cooperativa de Produção Agropecuária União do Oeste Cooperunião. Assentamento Conquista na Fronteira. Dionísio Cerqueira/SC, out. 1997.

PAULILO, Maria Ignez S. "O peso do trabalho leve". Ciência Hoje, Rio de Janeiro: SBPC, v. 05, n. 28, p. 64-70, 1987.

PAVAN, Dulcinéia. As Marias Sem-Terra: trajetórias e experiências de vida de mulheres assentadas em Promissão/SP 1985/1996. 1998. Dissertação (Mestrado em História Social) - Pontifícia Universidade Católica de São Paulo.

PENA, Maria Valéria Junho. Mulheres e trabalhadoras: presença feminina na constituição do sistema fabril. Rio de Janeiro: Paz e Terra, 1981.

PERROT, Michelle. Os excluídos da história: operários, mulheres e prisioneiros. 2. ed. Tradução de Denise Bottmann. Rio de Janeiro: Paz e Terra, 1988.

. Mulheres públicas. Tradução de Roberto Leal Ferreira. São Paulo: UNESP, 1998.

SADER, Eder. Quando novos personagens entraram em cena: experiências, falas e lutas dos trabalhadores da Grande São Paulo, 1970-1980. Rio de Janeiro: Paz e Terra, 1988.

SCHWADE, Elisete. "A luta não faz parte da vida... é a vida": o projeto político-religioso de um assentamento no Oeste Catarinense. 1993. Dissertação (Mestrado em Antropologia Social) - Universidade Federal de Santa Catarina, Florianópolis.

SILVA, Cristiani Bereta da. As fissuras na construção do "novo homem" e da "nova mulher": relações de gênero e subjetividades no devir MST - 1979-2000. 2003. Tese (Doutorado em História) - Programa de Pós-Graduação em História, Universidade Federal de Santa Catarina, Florianópolis.

VEYNE, Paul. Como se escreve a história: Foucault revoluciona a história. Tradução de Alda Baltar e Maria Auxiliadora Kneipp. 4. ed. Brasília: Ed. da UnB, 1998.

\section{Gender Relations and Subjectivities in the Building of Brazil's Landless Movement}

Abstract: The internal reports of MST and the many different publications about this Movement, produced in the last 20 years, reveal the processes and the many different issues that appeared among the dispute for a piece of land. Many worries have been added to the main concern that is about the lack of land. Ideas, practices and political concerns have emerged in this movement that is still in construction. This study is a critical exercise of reflection about the nature of these productions and of the quotidian relations about the endeavours of constructing new subjects. It tries to investigate how were the changes being constructed in the work, social and political relations as well as in the affective relationships of men $X$ women, women $X$ women and men $X$ men inside the MST.

Key words: social movement, gender, subject, subjectivities. 